\title{
Chronic hepatitis C: future treatment
}

This article was published in the following Dove Press journal:

Clinical Pharmacology:Advances and Applications

8 January 2014

Number of times this article has been viewed

\section{Astrid Wendt \\ Xavier Adhoute \\ Paul Castellani \\ Valerie Oules \\ Christelle Ansaldi \\ Souad Benali \\ Marc Bourlière}

Department of HepatoGastroenterology, Hôpital

Saint-Joseph, Marseille, France
Correspondence: Marc Bourlière Department of Hepato-

Gastroenterology, Hôpital Saint-Joseph, 26, boulevard de Louvain, I 3285 Marseille cedex 08, France

Email mbourliere@hopital-saint-joseph.fr
Abstract: The launch of first-generation protease inhibitors (PIs) is a major step forward in HCV treatment. However, the major advance is up to now restricted to genotype 1 (GT-1) patients. The development of second-wave and second-generation PIs yields higher antiviral potency through plurigenotypic activity, more convenient daily administration, fewer side effects and, for the second-generation PIs, potential activity against resistance-associated variants. NS5B inhibitors include nucleoside/nucleotide inhibitors (NIs) and non-nucleotide inhibitors (NNIs). NIs have high efficacy across all genotypes. Sofosbuvir has highly potent antiviral activity across all genotypes in association with pegylated interferon and ribavirin (PR), thus allowing shortened treatment duration. NS5A inhibitors (NS5A.I) have highly potent antiviral activity. It has recently been shown for the first time that NS5A.I in combination with protease inhibitors can cure GT-1b null responders in an interferon-free regimen. Besides, several studies demonstrate that interferon (IFN)-free regimens with direct-acting antiviral agent combinations are able to cure a large number of either naïve or treatment-experienced GT-1 patients. Moreover, quadruple regimen with PR is able to cure almost all GT-1 null responders. The development of pan-genotypic direct-acting antiviral agents (NIs or NS5A.I) allows new combinations with or without PR that increase the rate of sustained virological response for all patients, even for those with cirrhosis and independently of the genotype. Therefore, the near future of HCV treatment looks promising. The purpose of this article is to provide an overview of the clinical results recently reported for HCV treatment.

Keywords: SVR, direct antiviral agents, host-targeting agents, interferon-free regimen, pangenotypic activity, cirrhosis

\section{Introduction}

Approximately 170-200 million people worldwide (3\% of the world population) are chronically infected with the hepatitis $\mathrm{C}$ virus (HCV). ${ }^{1} \mathrm{HCV}$ prevalence and genotype distribution vary around the world. Among the six identified HCV genotypes, genotype 1 (GT-1) is the most prevalent worldwide; it was the most difficult to cure with the standard of care treatment: the combination of pegylated interferon (PEG-INF) alpha and ribavirin (RBV).

Chronic hepatitis $\mathrm{C}$ can lead to cirrhosis and subsequent complications such as hepatocellular carcinoma (HCC). Every year, more than 350,000 people woldwide die from hepatitis C-related liver diseases. The goal of HCV treatment is to achieve a sustained virological response (SVR), which is defined as undetectable HCV RNA, 6 months after cessation of therapy, leading to HCV clearance. SVR is associated with an improved histological outcome, and a reduction of morbidity and mortality. submit your manuscript | www.dovepress.com

Dovepress

http://dx.doi.org// 0.2147/CPAA.S30338
Clinical Pharmacology: Advances and Applications 2014:6 I-I7

(C) 2014 Wendt et al, publisher and licensee Dove Medical Press Ltd. This is an Open Access article which permits unrestricted noncommercial use, provided the original work is properly cited. 
In 2011, the launch of the two first-generation protease inhibitors (PIs), boceprevir and telaprevir, was a major step forward for the treatment of GT-1-infected patients. Associated with PEG-INF/RBV therapy (PR), these two drugs increase the chance of cure for naïve patients by $30 \% .{ }^{2-4}$ The benefit is even greater in treatment-experienced patients: the chance of cure increases by $50 \%-60 \%$ for relapsers, $40 \%-45 \%$ for partial responders, and $25 \%$ for null responders. ${ }^{5,6}$ However, only GT-1 patients benefit from this major advance. For the 50-70 million people infected with other HCV genotypes, the combination of PR remains the current standard-of-care (SOC) treatment. ${ }^{7}$ The development of more effective treatments for non-GT-1 patients is essential, especially for GT-4 patients for whom SVR rates are relatively low with PR.

Different potential therapeutic targets in HCV life cycle have been identified. This has led to the development of both direct antiviral agents (DAA) and agents targeting the host functions, which are essential for viral replication. Besides the first-generation PIs boceprevir and telaprevir, DAA comprise second-wave and second-generation PIs, nucleos(t)-ide (NI) and non-nucleoside (NNI) inhibitors of the NS5B complex, and NS5A-inhibitors (NS5A.I). Host-targeting agents (HTA) are, for example, cyclophilin inhibitors and silibinin. Next-generation DAAs appear to be promising; they may enable interferon-free (INF-free) regimens for cirrhotic patients and even for patients with more advanced or decompensated cirrhosis.

The purpose of this article is to provide an overview of the recent clinical results concerning future HCV treatment of GT-1, non-GT-1, and cirrhotic patients.

\section{Treatment of GT-I patients beyond boceprevir and telaprevir}

Triple therapy including boceprevir or telaprevir in combination with PR increases the SVR rates by $30 \%$ for naïve patients, and even more for treatment-experienced patients. However, this benefit is associated with the increase of side effects such as anemia and with the onset of new side effects: dysgeusia (nearly one-third of the patients treated with boceprevir) and cutaneous rash (55\% of the patients treated with telaprevir). ${ }^{8}$ Moreover, the triple regimen results in the increase of treatment withdrawals due to adverse events. Concerning anemia management, these new treatments have led to a new paradigm: for noncirrhotic patients, the ribavirin dose can be reduced without impairing SVR, even at early stages of treatment when HCV RNA is still detectable. ${ }^{9-11}$

\section{Second-wave and second-generation Pls}

The main weaknesses of the first-generation PIs are their low genetic barrier to resistance and the fact that their effectiveness is limited to GT-1 patients. Second-wave PIs have a higher barrier to resistance, better activity against multiple genotypes except GT-3, more convenient dosing schedules, and improved safety and tolerance. ${ }^{12-14}$ Second-generation PIs are compounds that are broadly active against all genotypes and against viral isolates which carry resistance mutations for first-generation PIs. ${ }^{15-26}$ In combination with PR, the new PIs appear to achieve greater SVR rates than the first-generation PIs. These new treatments allow for more convenient administration schedules (one or two administrations per day); this could result in improved pharmacokinetics and better patient compliance. Besides, the safety profile seems to be good. The pan-genotypic activity of this new treatment provides new therapeutic options for a greater number of patients, in particular for those infected with GT-4..$^{25,27-29}$

See Table 1 for an overview of the efficacy and the tolerance of the second-wave PIs, which are currently developed. Second-generation PIs are in early stage of development. MK-5172 in monotherapy demonstrates pan-genotypic activity ${ }^{29}$ other molecules such as ACH-2684, AVL-181, and AVL-192 show promising results in vitro. ${ }^{30}$

\section{NS5B polymerase-inhibitors (NS5B.I)}

NS5B nucleoside/nucleotide inhibitors (Nls)

NIs mimic natural polymerase substrates and bind to NS5B active sites, thereby causing chain termination and increasing the number of errors when incorporated into a growing RNA chain. As these NS5B sites are well conserved among genotypes, NIs tend to have activity across all genotypes. ${ }^{31}$ They also have the highest barrier to resistance of all DAAs so far.

The first NI developed was the nucleoside analog mericitabine. In triple regimen with PR, mericitabine shows less antiviral activity for GT-1 patients compared to triple regimen with PIs. ${ }^{32,33}$ However, it has high antiviral activity for GT-2 and GT-3 treatment-experienced patients and for GT-4 patients ${ }^{34}$ (Table 2). If included in the INF-free regimen with ritonavir-boosted danoprevir and ribavirin for treatment-experienced GT-1b patients, or in quadruple therapy with boosted danoprevir and PR for treatmentexperienced GT-1 patients, mericitabine leads to promising SVR rates ${ }^{20}$ (Table 3).

The pyrimidine nucleotide analog sofosbuvir has highly potent pan-genotypic antiviral activity and a high genetic barrier to resistance. In combination with ribavirin in an INF-free regimen for 12 weeks, sofosbuvir achieves SVR 
rates from $84 \%$ to $100 \%$ for GT-1, GT-2, and GT-3 naïve patients. For treatment-experienced GT-1 patients, SVR rates are lower (11\%); almost all patients relapse after treatment discontinuation. ${ }^{35,36}$ Triple regimen with PR for GT-1, GT-2, GT-3, GT-4, and GT-6 naïve patients achieves SVR rates from $88 \%-100 \%{ }^{37-39}$ (Table 2). At the moment, sofosbuvir is also used in combination with PIs or NS5A.I (with or without ribavirin).

\section{Non-nucleotide inhibitors (NNIs)}

NNIs have a restricted spectrum of activity against the various genotypes, and a low barrier to resistance. They are active against GT-1, with less antiviral activity for GT-1a infected patients than for GT-1b infected patients. Table 2 gives an overview of the clinical efficacy of NNIs in combination with PR. ${ }^{40-45}$ They appear to have less antiviral activity compared to triple regimen with PIs or NS5A.I. Nevertheless, the fact that they target five different sites of the NS5B-polyprotein suggests that combinations with other NNIs or with different DAAs (PIs or NS5A.I) could be effective.

\section{NS5A-complex-inhibitors (NS5A.I)}

HCV NS5A is a phosphoprotein. It does not possess any enzymatic function, but has a crucial role in HCV replication. NS5A is comprised of three structural domains as well as an amphipathic alpha helix that functions in membrane localization. Domain I is essential for viral RNA replication. Domain II is involved in the binding to cyclophilin A. It has been postulated to play a role in antagonizing the innate immune response to $\mathrm{HCV}$. Domain III seems to be important for the assembly of infectious viral particles. ${ }^{46}$ The first-in-class NS5A.I daclatasvir shows potent pan-genotypic antiviral activity. It has a low barrier to resistance. Especially GT-1a patients can select resistance-associated variants (RAVs) after a single administration.

In triple therapy with PR, daclatasvir demonstrates high antiviral potency for GT-1 and GT-4 naïve patients ${ }^{47}$ (Table 4). Studies with treatment-experienced GT-1 patients and with GT-2/3 are still ongoing. ${ }^{48,49}$

Quadruple therapy with daclatasvir in association with the PI asunaprevir and PR for 24 weeks results in SVR rates of more than $90 \%$ for GT-1 null responders (who are the most difficult to treat). ${ }^{26,50}$ However, this approach is feasible only for patients who can tolerate PEG-INF and ribavirin. For cirrhotic patients, response rates are likely to be lower, while adverse event rates are probably higher.
Several INF-free regimens with daclatasvir have been studied. Dual therapy with daclatasvir and asunaprevir for 24 weeks achieves SVR for $65 \%-78 \%$ of GT-1b patients who are previous null responders. ${ }^{50}$ Dual or triple therapy with daclatasvir or sofosbuvir (with or without ribavirin) for 24 weeks achieves SVR for $93 \%-100 \%$ of naïve GT-1 patients and for $83 \%-100 \%$ of naïve GT-2/3 patients. $^{51}$

Other NS5A.I are currently in development. In association with PR, ABT-267 shows promising on-treatment results. ${ }^{52}$ Ledipasvir has been studied in quadruple regimen, either with PI and PR or in INF-free regimen with PI, NNI, and ribavirin. ${ }^{53}$ Second-generation NS5A.I, including MK-8742 and ACH-3102, have been developed, but clinical results are pending.

\section{Host targeting agents (HTA) and other antiviral treatments}

Cyclophilins are a highly conserved family of human enzymes involved in cellular processes associated with protein folding, transport, and secretion, as well as mitochondrial function and immune response. ${ }^{54} \mathrm{HCV}$ can coopt cyclophilins as cofactors for viral replication. In the hepatocyte, cyclophilin A and B bind with the viral proteins NS5A, NS5B, and NS2 to form a replication complex mediating the correct folding and trafficking of $\mathrm{HCV}$ proteins. Thus they are functioning as a positive modulator for HCV replication. ${ }^{55}$ Alisporivir (Debio 025) (ALV) is a nonimmunsuppressive form of cyclophilin inhibitor that shows a potent antiviral activity for many HCV genotypes, low resistance rates without cross-resistance to PI, NS5B.I, and NS5A.I. Phase II studies show increased SVR rates compared to PR for naïve G1 patients receiving a combination of ALV and PR for at least 24 weeks. For GT-1 treatment-experienced patients, ALV + PR demonstrated higher complete early virological response compared to PR in relapsers, partial responders, and null responders. ${ }^{56}$ Moreover, for GT-2/3 naïve patients, the possibility of an INF-free regimen has been studied. ${ }^{57}$ Among patients treated with only ALV or with RBV in combination, 22\%-34\% reach rapid virological response (RVR) and undergo 24 weeks of INF-free treatment. SVR in this subgroup varies from $82 \%$ to $91 \%$. These results demonstrate the ability of such a regimen to cure these patients. ${ }^{57}$ In the Phase II program, ALV appears to have a good safety profile, with rare cases of hyperbilirubinemia. However, during the Phase III program in April 2012, the US Food and Drug Administration (FDA) placed the ALV program on a full clinical hold and, all patients discontinued therapy. This was due to 


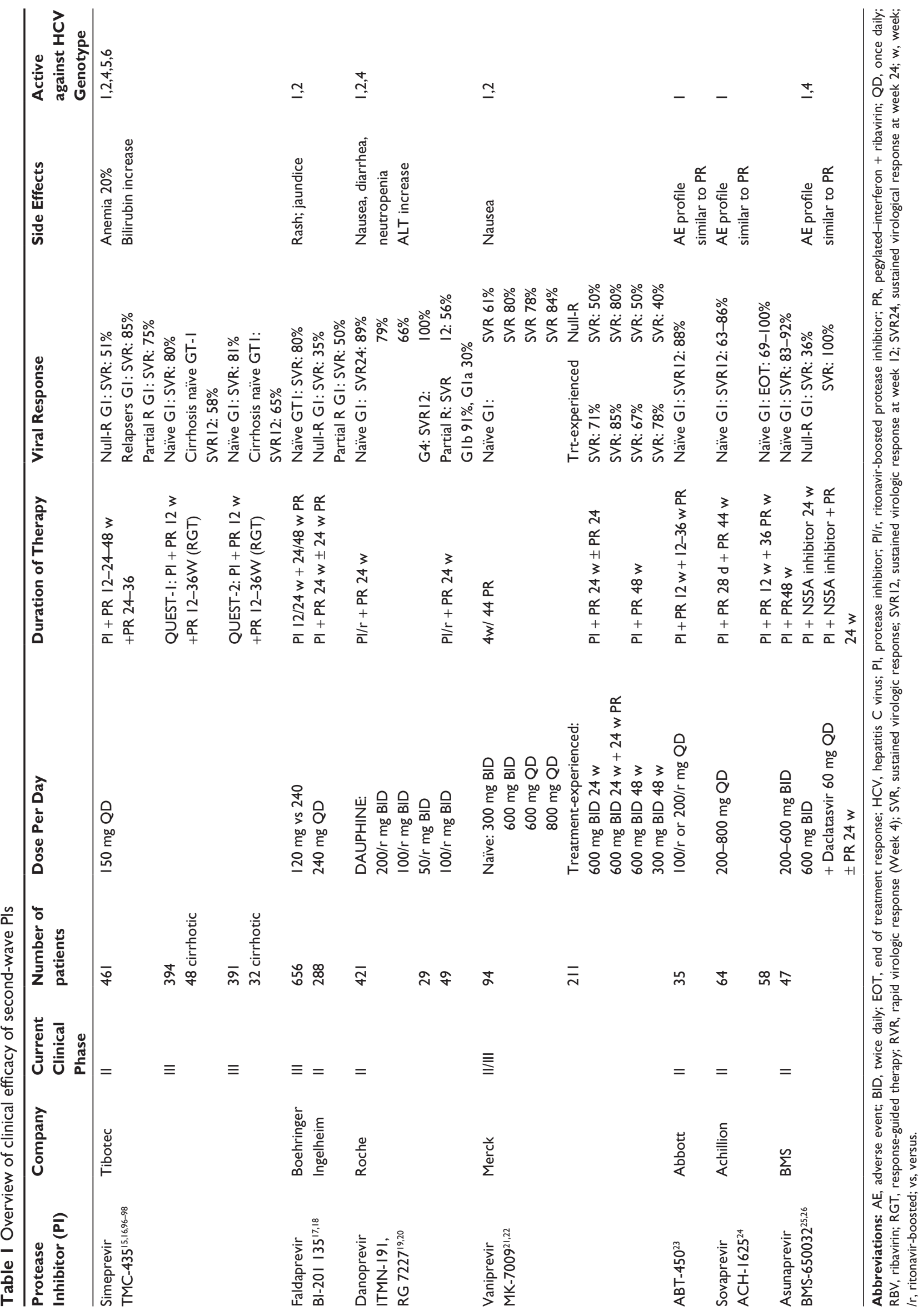




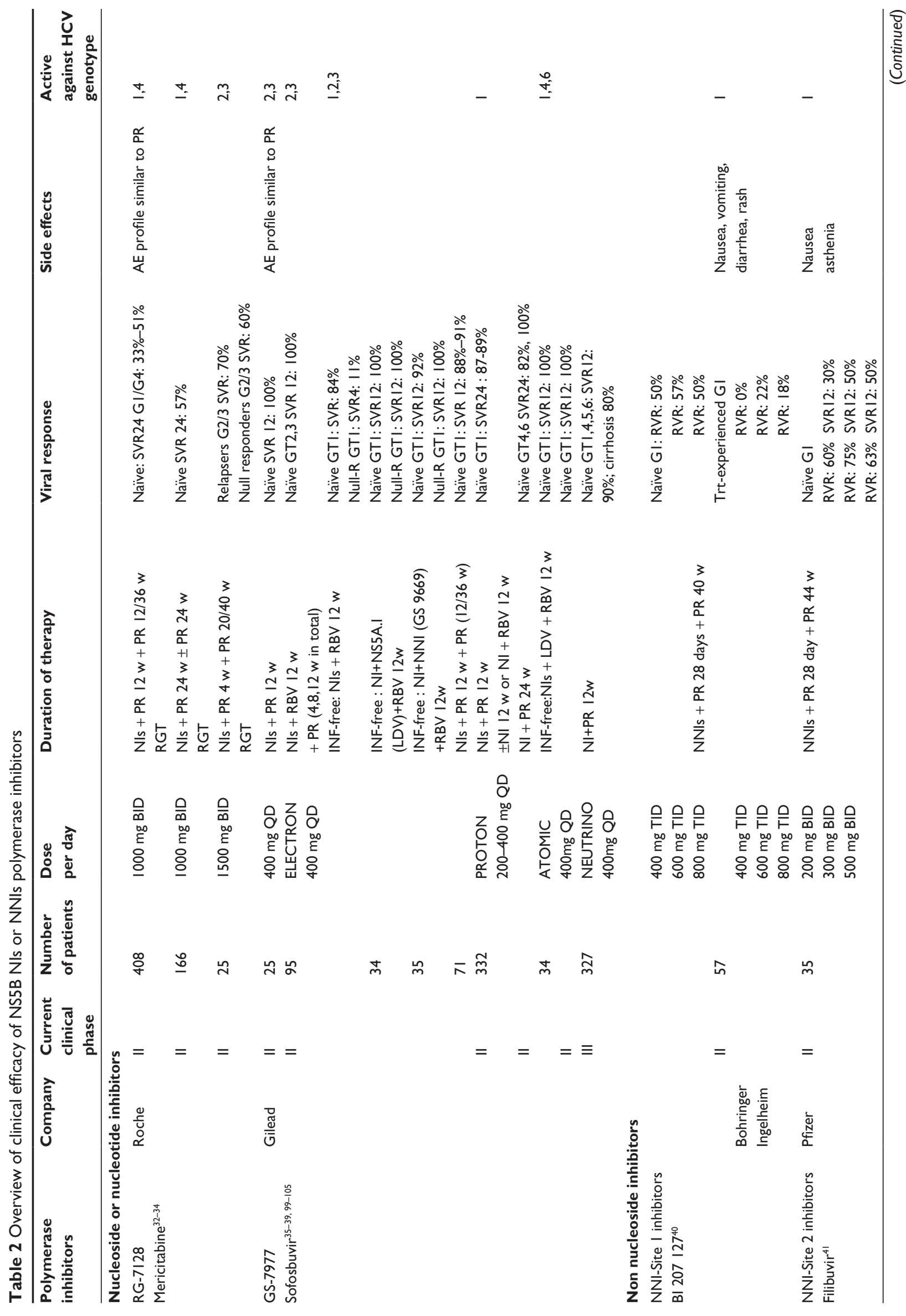




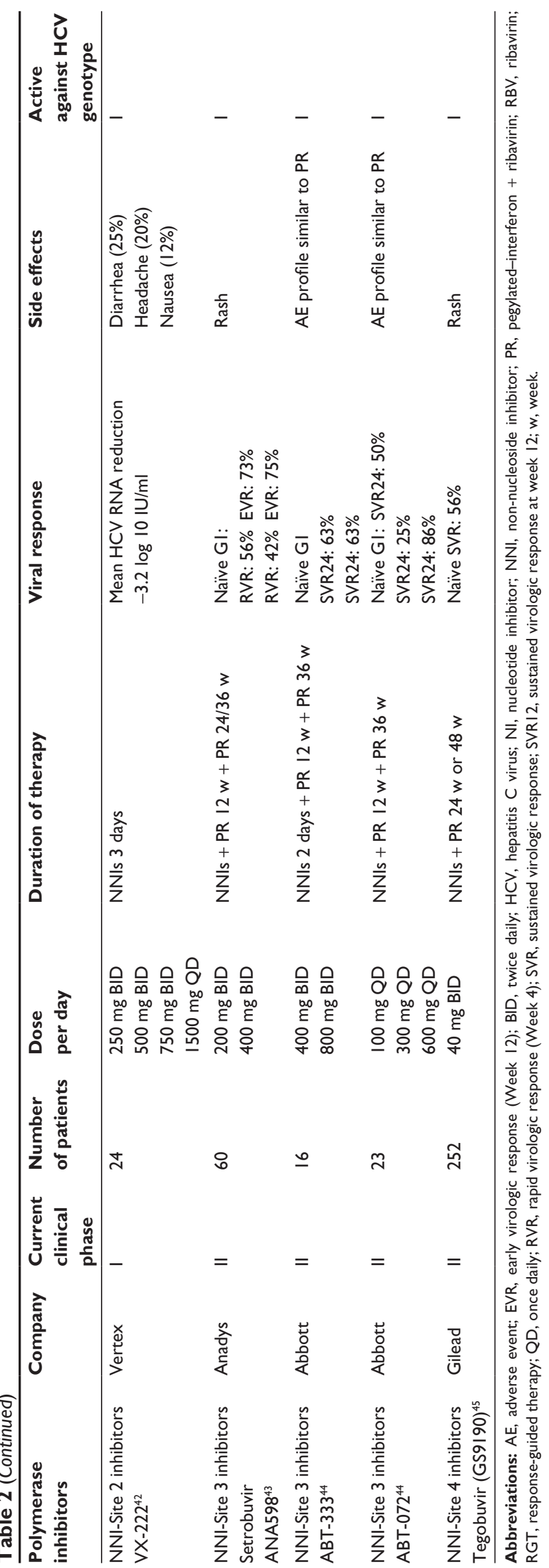

a cluster of three cases of acute pancreatitis, one of them fatal, in the treatment group receiving ALV and PR. Two other cyclophilin inhibitors are currently in development (SCY-635, NIM-811). Cyclophilin inhibitors could be an important addition to DAAs in treatment combinations; they may be able to shorten and simplify therapy. They have the potential to be a cornerstone drug for an IFN-free regimen in combination with DAAs, because they have a high barrier to resistance, no cross-resistance with DAAs, and a pan-genotypic activity. ALV development is likely to move forward, but will not be used in association with PEG-INF because of the potential risk of acute pancreatitis.

Therapeutic vaccines fail to show any significant positive results yet. GI-5005 is not able to increase SVR compared to PR alone, except in a subgroup of difficultto-treat patients. Other vaccines, such as ChronVac-C, IC41, and TG-4040, demonstrate limited antiviral activity. ${ }^{30,58}$ Polyclonal and monoclonal antibodies do not reach any endpoint in trials evaluating recurrence after liver transplantation. Toll-like receptors may enhance the host immune system against $\mathrm{HCV}$; they are currently in the early development phase.

Silibinin is a flavonoid compound targeting the host cell. It is a direct inhibitor of HCV RNA-dependent RNA polymerase and a blocker of virus entry and transmission. It was recently proved to be successful in the treatment of previous PR nonresponders. ${ }^{59}$

Peg interferon lambda has the same antiviral efficacy as PEG-INF alpha, but significantly reduces side effects for GT-1 and GT-4 patients (even if they are cirrhotic) ${ }^{60}$ It may become a new alternative in combination with DAAs.

\section{DAA combinations: the challenge of INF-free regimens}

Most DAAs currently being developed for HCV treatment have been initially tested in combination with PR. The rationale of combination therapy is to increase viral potency, to decrease viral resistance, and to avoid the use of PEG-INF.

INF-related side effects remain a major problem in clinical routine. They often affect the patient's compliance and hinder treatment in cirrhotic patients or in those with HCVrecurrence after liver transplantation. DAA combinations may permit association of molecules with different mechanism of action, different resistance profiles, and high antiviral activity.

An overview of the efficacy and tolerability of DAA combination treatments with or without PEG-INF is outlined in Table 3. ${ }^{20,26,50,51,53,61-74}$ 


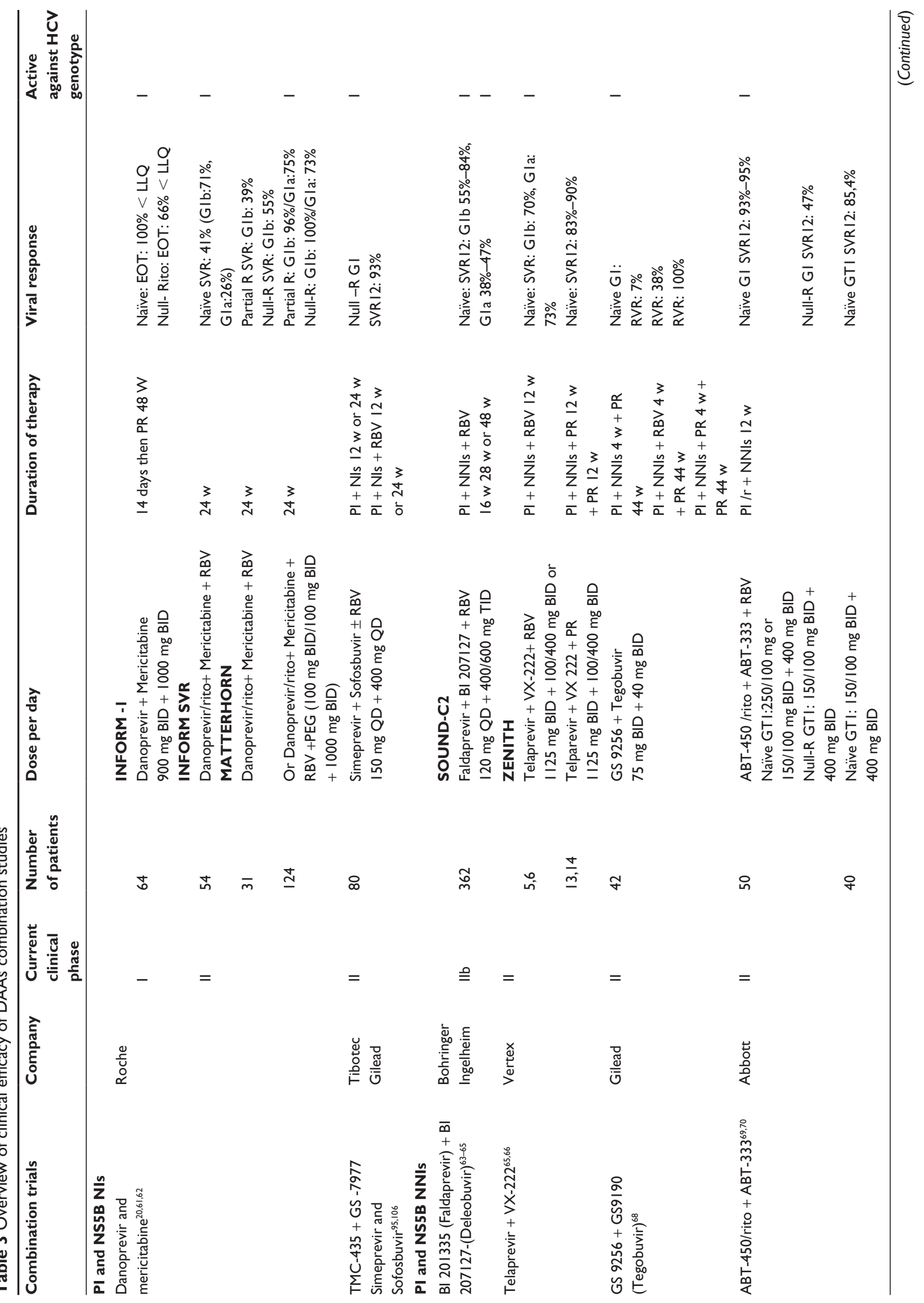




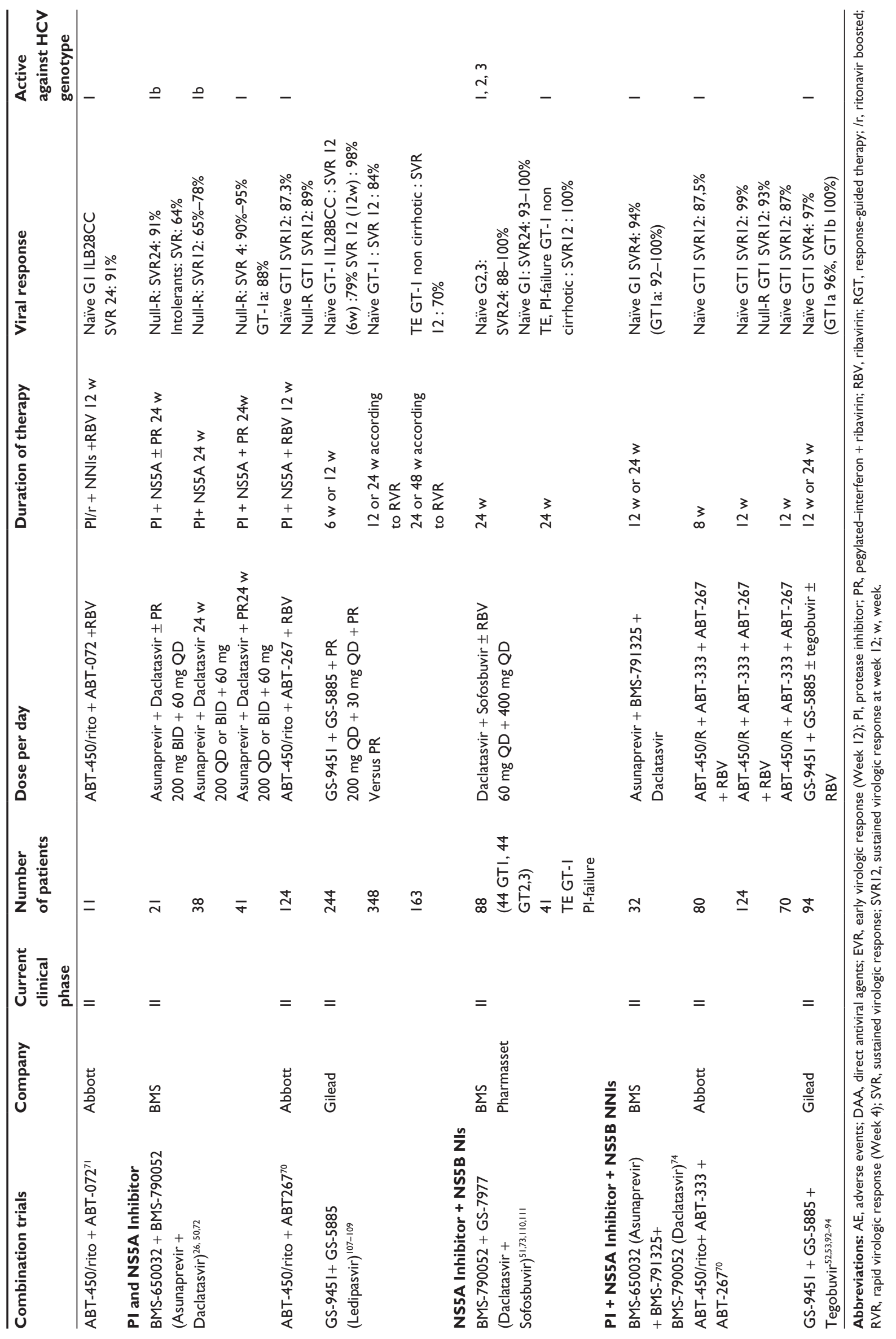




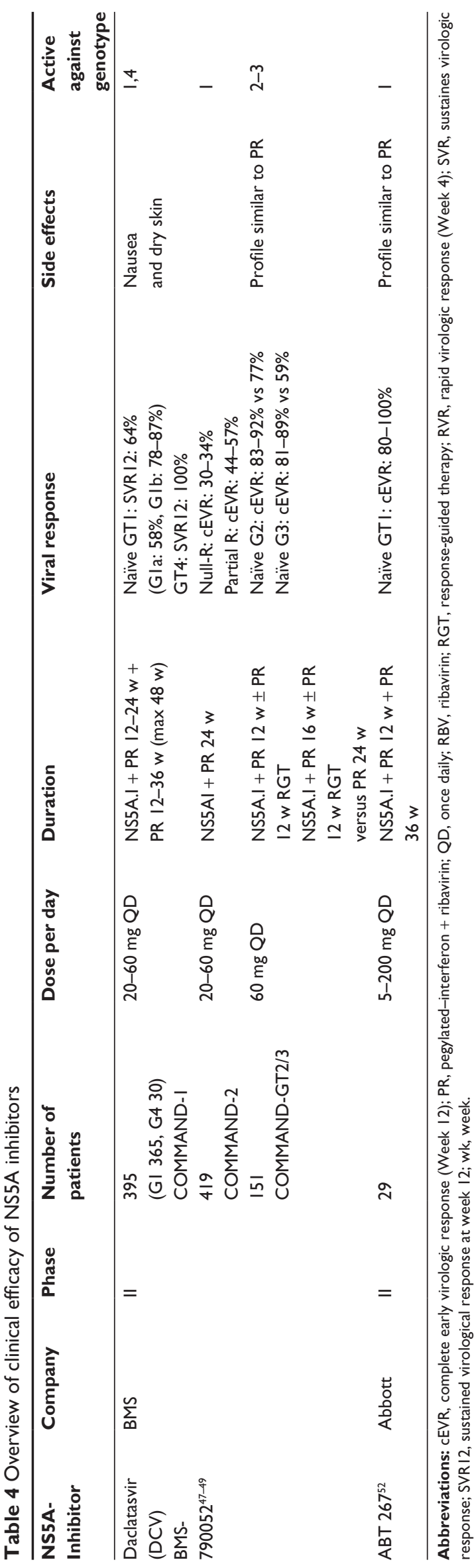

\section{Quadruple therapy with PEG-INF}

Four studies ${ }^{20,26,50,75}$ have been reported so far. The first study (quadruple regimen, associating asunaprevir [PI], daclatasvir [NS5A.I], and PR for 24 weeks for previous GT-1 null responders) reports SVR rates over $90 \%$. The second study by Gilead (associating a PI, a NS5A.I, and PR for treatment duration of 6 to 24 weeks for naïve GT-1 patients) is ongoing.

Two studies combining a PI, an NS5B.I, and PR for GT-1 patients have been reported. Telaprevir (PI) plus VX-222 (NNI) and PR for 12 weeks followed by 12 weeks PR leads to SVR rates of $83 \%-90 \%$ for GT-1 naïve patients. ${ }^{75}$ Ritonavirboosted danoprevir (PI/r) in combination with mericitabine (NI) and PR for 24 weeks leads to SVR rates of $75 \%-96 \%$ for GT-1 previous partial responders and to SVR rates of $73 \%-100 \%$ for GT-1 previous null responders. Overall, the results of quadruple therapy with PEG-INF show SVR rates over $90 \%$ for the most difficult-to-cure patients and a reasonable safety profile. ${ }^{20}$

\section{Two DAAs in INF-free regimens}

The first proof of concept of INF-free regimens was given by the INFORM-1 study, which demonstrates that 13 days of dual therapy with danoprevir and mericitabine are able to induce a $5.1 \log _{10} \mathrm{IU} / \mathrm{mL}$ decline from baseline for naïve GT-1 patients and a $4.9 \log _{10} \mathrm{IU} / \mathrm{mL}$ decline from baseline for treatment-experienced null responders. ${ }^{61}$ A full dual therapy with asunaprevir (PI) and daclatasvir (NS5A.I) without INF for GT-1b treatment-experienced null responders for 24 weeks shows SVR12 rates from $65 \%-78 \%$ up to $91 \%$ (depending on the asunaprevir dosage) ${ }^{26,50,72}$ Recently, a dual therapy with daclatasvir (NS5A.I) and sofosbuvir (NI) for 24 weeks demonstrated SVR rates from $93 \%-100 \%$ for GT-1 naïve patients. ${ }^{51}$ Currently, a study with simeprevir and sofosbuvir for 12 or 24 weeks for GT-1 null responders is being conducted (Table 3).

\section{Two DAAs and RBV in INF-free regimens}

Four studies combine PIs, NNIs, and RBV (Table 3). The largest trial involves 362 GT-1 naïve patients. They are treated with faldaprevir (PI), BI-207127 (NNI), and RBV for 16 to 48 weeks. SVR rates range from $55 \%$ to $84 \%$ for GT- $1 \mathrm{~b}$ patients and from $38 \%$ to $47 \%$ in GT-1a patients. A second-wave ritonavir-boosted PI (ABT-450) in association with NNIs and RBV for 12 weeks can achieve SVR rates of over $90 \%$ for GT-1 naïve patients (regardless of the HCV subtype 1a or 1b). However, SVR rate was lower in GT-1 null responders. 
This suggests that such a combination is not optimal for this difficult-to-treat population.

The combination of ritonavir-boosted ABT-450 (PI), ABT-267 (NS5A.I), and RBV for 12 weeks increases SVR rates up to $89 \%$ for null responders.

The addition of RBV to the combination of daclatasvir (NS5A.I) and sofosbuvir (NI) for 24 weeks did not increase the SVR rate compared to dual therapy for GT-1 naïve patients.

\section{Three DAAs with or without RBV in INF-free regimens}

Three studies ${ }^{53,70,74}$ combine a second-wave PI, an NS5B.I, and an NS5A.I with or without RBV. The first study by Gilead et al on naïve GT-1 patients associates GS-9451 (secondwave PI), ledipasvir (NS5A.I) and tegobuvir (NNI) with or without RBV for 12 or 24 weeks; the SVR-rate is $97 \%$. The second Phase II study associates asunaprevir (PI), daclatasvir (NS5A.I), and BMS-790052 (NNI) for 12 or 24 weeks for GT-1 naïve patients; the SVR rate is $94 \%$. The third study associates a second-wave ritonavir-boosted PI (ABT-450/r), ABT-333 (NNI), ABT-267 (NS5A.I), and RBV for 12 weeks for GT-1 naïve or treatment-experienced patients; the SVR rate is $99 \%$ for GT-1 naïve patients and 93\% for GT-1 null responders. The safety profiles of these regimens appear to be good.

\section{Treatment of non-GT-I patients}

The treatment of non-GT1 patients is based on PR, which remains the SOC treatment. ${ }^{7}$ Worldwide, between 50 and 70 million individuals are chronically infected with $\mathrm{HCV}$ GT-2 to GT-6. ${ }^{76}$ In some countries such as Egypt, the HCV patients have almost exclusively GT-4.

In observational cohorts like the PROPHESYS-cohort, the SVR rates are $41 \%, 61 \%, 59 \%-68 \%$, and $71 \%$ for GT-4, GT-3, GT-5/6, and GT-2 patients, respectively. ${ }^{77}$ The GT-4 patients are currently the most difficult to treat. New treatments are needed for unsuccessfully treated non-GT-1 patients: currently, the only option is a second course of PR, which results in poor SVR rates (19\% to $34 \%$ for nonresponders and $46 \%$ for relapsers). ${ }^{78}$

\section{Telaprevir and boceprevir in non-GT-I patients}

Telaprevir monotherapy has an antiviral activity against HCV GT-2, but not against GT-3. ${ }^{79}$ Triple therapy with telaprevir for 2 weeks for GT-2 patients leads to a greater drop of HCV RNA level compared to the SOC treatment. ${ }^{79}$ In a Phase IIa study with 24 GT-4 patients, triple therapy with telaprevir for 2 weeks induces a greater reduction of HCV RNA level compared to the SOC treatment. However, after the continuation of PR for 46 weeks, the SVR rates do not increase compared to the SOC treatment. ${ }^{80}$ The data on treatment with boceprevir is limited. Boceprevir monotherapy for 2 weeks induces a significant viral drop for GT-3 patients. ${ }^{81}$ However, no Phase II study exists for this population. Triple regimens with first-generation PIs have at most limited antiviral effectiveness in GT-3 and GT-4 patients; this confirms the need for more potent combinations with pan- or plurigenotypic activity.

\section{Beyond first-generation Pls}

The second-wave and second-generation PIs seem to have a better activity against multiple genotypes. Second-wave PIs have no activity against GT-3 but a good efficacy on GT-4 patients. Second-generation PIs (MK-5172, ACH-2684, AVL-181, AVL-192) are effective against all HCV genotypes in vitro. ${ }^{82}$

NIs (mericitabine and sofosbuvir) have similar efficacy against all genotypes and the highest barrier of resistance. Therefore, they appear to be among the most promising pangenotypic drugs. ${ }^{35}$ On the other hand, NNIs demonstrate no antiviral activity against non-GT-1 patients.

NS5A.I also have an antiviral efficacy against all genotypes. ${ }^{46}$ The first-in-class NS5A.I demonstrate potent antiviral efficacy in triple regimen and in IFN-free regimen against GT-2, GT-3, and GT-4.

HTAs such as alisporivir demonstrate antiviral activities against GT-2, GT-3, and GT-4. ${ }^{83}$

\section{Future GT-2 treatment}

Simeprevir (TMC-435) monotherapy for 7 days demonstrates weak antiviral activity against GT-2 patients. ${ }^{84}$ MK-5172 appears to be more promising in this setting. A combination study with PR for 12 or 24 weeks is ongoing. After 4 weeks of triple regimen with mericitabine and PR for GT-2/3 treatment-failure patients, the RVR rate is $95 \%$ in the mericitabine arm versus $60 \%$ in the PR arm. Due to the short duration of the triple regimen, the high RVR rate does not transfer to a high SVR rate (only 63\%). ${ }^{34}$ Sofosbuvir (GS-7977) $400 \mathrm{mg}$ QD in association with PR for 12 weeks induces in Phase II studies an SVR for all patients. The same SVR rate is reached when naïve patients are treated in an IFN-free regimen with sofosbuvir and RBV for 12 weeks. ${ }^{35}$ For treatmentexperienced patients, the same regimen for 12 weeks leads to an SVR rate of $68 \%$. In Phase III studies (POSITRON and 
FISSION), IFN-free regimen with sofosbuvir and RBV for 12 weeks yields an SVR rate of 92\%-97\% for GT-2 naïve patients. For this population, IFN-free regimen with a combination of an NS5A.I and an NI appears to be of interest. A Phase II study combining daclatasvir and sofosbuvir with or without RBV for 24 weeks conducted with 44 GT-2 and GT-3 naïve patients demonstrates a 100\% SVR rate among patients treated with DAAs only. The study shows that RBV, if added to this combination, does not increase the SVR rate. ${ }^{51}$ HTAs such as alisporivir may also play an important role in combination with DAAs. In a Phase II study (VITAL), 346 GT-2 and GT-3 naïve patients are randomized in 5 groups with different doses of ALV only or in combination with RBV with or without PEG-INF. In the three IFN-free arms, 22\%, $23 \%$, and $34 \%$ of the patients reach RVR and are therefore maintained on the IFN-free regimen until week 24. Twelve weeks after cessation of treatment, the SVR rates range from $82 \%$ to $93 \%$.

This data suggests that the majority of GT- 2 patients may soon be cured with a short course of DAA combination with or without RBV.

\section{Future GT-3 treatment}

Second-wave PIs have no effects on GT-3 patients. MK-5172 appears to be more promising; a combination study with PR for 12 or 24 weeks is ongoing. For GT-2 and GT-3 treatmentfailure patients, 4 weeks of triple regimen with mericitabine and PR achieves an RVR rate of $95 \%$ (versus $60 \%$ for the PR arm). Again, the high RVR rate does not transfer to a high SVR rate (only 63\%) due to the short duration of the triple regimen (see Future GT-2 treatment). ${ }^{34}$ In Phase II studies, sofosbuvir (GS-7977) $400 \mathrm{mg}$ QD in association with PR for 12 weeks induces SVR for all patients. The same SVR rate is reached when naïve patients are treated in an IFN-free regimen with sofosbuvir and RBV for 12 weeks (see Future GT-2 treatment). ${ }^{35}$ SVR rates drop to $60 \%$ if sofosbuvir is used alone or if the RBV dose is reduced to $600 \mathrm{mg}$ daily. As outlined in Section IIIc, the same regimen for 12 weeks leads to an SVR rate of $68 \%$ for treatment-experienced patients. In Phase III studies (POSITRON and FISSION), IFN-free regimen with sofosbuvir and RBV for 12 weeks results in an SVR rate of $56 \%-61 \%$ for GT-3 naïve patients. These results suggest that GT-3 patients are more difficult to cure with such short IFN-free regimens; a longer duration of treatment and association with other DAAs (like pan-genotypic NS5A.I) is needed. A Phase II study combining daclatasvir and sofosbuvir with or without RBV for 24 weeks conducted with 44 GT-2 and GT-3 naïve patients demonstrates a $100 \%$ SVR rate among patients treated with DAAs only. The study shows that RBV, if added to this combination, does not increase the SVR rate ${ }^{51}$ HTAs such as alisporivir may also play an important role in combination with DAAs. In a Phase II study (VITAL), 346 GT-2 and GT-3 naïve patients are randomized in five groups with different doses of ALV only or in combination with RBV with or without PEG-INF. In the three IFN-free arms, 22\%, 23\%, and 34\% of the patients reach RVR and are therefore maintained on the IFN-free regimen until week 24. Twelve weeks after cessation of treatment, the SVR rates range from $82 \%$ to 93\% (see Future GT-2 treatment).

As for GT-2 patients, this data suggests that the majority of GT-3 patients may soon be cured with a short course of DAA combination with or without RBV. However, for some patients, combination therapy with PEG-INF and RBV is still required.

\section{Future GT-4 treatment}

Simeprevir monotherapy is able to induce a mean viral decrease of $3.52 \log _{10} \mathrm{IU} / \mathrm{mL}$ after 8 days of treatment for naïve GT-4 patients. ${ }^{84}$ Ritonavir-boosted danoprevir in association with PR for 24 weeks has cured all 29 GT-4 naïve patients treated so far. ${ }^{28}$ Asunaprevir is currently studied in an ongoing trial in combination with PR for various durations ( 24 to 48 weeks) for naïve GT-4 patients. Mericitabine in combination with PR appears to achieve comparable SVR rates to the SOC treatment for GT-4 naïve patients. ${ }^{85}$ Sofosbuvir $400 \mathrm{~g}$ daily in combination with PR for 24 weeks induces an end-of-treatment induces a SVR-rate of $82 \%$ in all eleven GT-4 naïve patients. ${ }^{39}$ Daclatasvir $60 \mathrm{mg}$ daily in association with PR for 24 weeks reaches SVR for all 12 GT-4 naïve patients. ${ }^{47}$ There are two ongoing studies with GT-4 treatment-experienced patients. The first one evaluates the combination of daclatasvir, asunaprevir, and PR for 24 weeks; the second one evaluates the combination of ritonavir-boosted danoprevir, mericitabine and PR for 24 weeks. Moreover, there are several ongoing studies with IFN-free regimens for GT-4 naïve patients: the combination of ABT-450/r (PI), ABT-267 (NS5A.I), and RBV for 12 weeks; the combination of asunaprevir, daclatasvir plus BMS-790052 (NNI) for 12 or 24 weeks; the combination of sofosbuvir, ledipasvir (NS5A.I), and RBV for 12 weeks.

In conclusion, clinical results with DAAs are sparse for GT-4 patients. However, the reported results are promising, and suggest that the vast majority of GT-4 patients can be cured either with triple or quadruple 
regimen including PR. Also, IFN-free DAA combinations including PIs, NS5A.I, and NIs may be a good option.

\section{Future GT-5 and GT-6 treatment}

Clinical results concerning the use of DAAs for GT- 5 and GT-6 HCV infections are limited.

Simeprevir monotherapy induces a significant mean decrease of viremia of $4.35 \log _{10} \mathrm{IU} / \mathrm{mL}$ after 8 days for the GT-6 patients; the mean decrease for GT-5 patients is only $2.19 \log _{10} \mathrm{IU} / \mathrm{mL}\left(2.71 \log _{10} \mathrm{IU} / \mathrm{mL}\right.$ at day 3$) .{ }^{84}$

Five GT-6 patients are included in the ATOMIC study. Under a combination therapy with sofosbuvir (GS-7977) $400 \mathrm{mg}$ QD, PEG-INF, and RBV for 24 weeks, both the RVR rate at week 4 and the SVR rate 12 weeks after the end of the treatment are $100 \%{ }^{86}$

\section{Cirrhotic patients}

Cirrhotic patients require $\mathrm{HCV}$ treatment most urgently: HCV-clearance allows both a significant decrease of fibrosis and potential cirrhosis reversal and a significant decrease of cirrhosis-related complications.

\section{Triple therapy with first-generation Pls}

GT-1 patients with severe fibrosis or compensated cirrhosis benefit from adequate triple therapy with first-generation PIs, even if the increase of the SVR rate is less significant than for noncirrhotic patients. ${ }^{2-6}$

Compared to PR, a triple therapy with boceprevir leads to an increase of the SVR rate of $14 \%$ for naïve GT- 1 cirrhotic patients. For patients with mild or moderate fibrosis, the SVR rate increases even by $30 \%{ }^{2}$ With telaprevir, the SVR rate increases by $10 \%-30 \%$ for cirrhotic patients, compared to $30 \%$ for noncirrhotic patients. ${ }^{3,4}$ Treatmentexperienced patients benefit more from triple therapy with either boceprevir or telaprevir if they are previous relapsers than if they are partial responders. ${ }^{5,6}$ For null responders, the benefit is limited, and needs to be weighted against the increase of side effects.

Cirrhosis is one of the negative predictive factors for the response to triple therapy. In Phase III studies with boceprevir and telaprevir, cirrhotic patients have lower RVR rates, more frequent relapses, and always require long fixed duration therapy (4 weeks of PR lead-in followed by 44 weeks of triple regimen with boceprevir; 12 weeks of triple regimen with telaprevir followed by 36 weeks of PR).

In Phase III studies, serious adverse events occur for approximately $10 \%$ of the patients with both drugs. Serious adverse events are higher for cirrhotic patients. (Note however, that the number of cirrhotic patients in these studies is limited.) In the real-life setting of the French CUPIC cohort, which includes more than 600 treatmentexperienced cirrhotic patients, it is demonstrated that the number of serious adverse events increases dramatically for cirrhotic patients after 16 weeks of treatments: by $38 \%$ with boceprevir and by $49 \%$ with telaprevir. ${ }^{87}$ Six patients died, mainly related to infection or hepatic decompensation. In multivariate analysis, two baseline factors are predictive for death infection or hepatic decompensation: platelet count $<100,000 / \mathrm{mm}^{3}$ and serum albumin level $<35 \mathrm{~g} / \mathrm{L}$. As expected, anemia is frequent and severe for cirrhotic patients treated with PIs in the CUPIC cohort. Despite the use of erythropoietin for nearly half of the patients, blood transfusion rate is high $(6.3 \%$ with boceprevir and $16 \%$ with telaprevir after 16 weeks of treatment). This can partly be explained by the relatively small number of patients for whom the RBV dose was reduced (10\% with boceprevir and $13 \%$ with telaprevir). The ITT analysis of preliminary virological results at week 16 shows that $67 \%$ of the patients treated with telaprevir and $58 \%$ of patients treated with boceprevir have undetectable HCV RNA. These good results need to be balanced with safety issues. Overall, triple therapy is feasible for cirrhotic patients who need to be carefully and frequently monitored during treatment.

Little data is available concerning the use of triple regimens in the post-transplant setting. ${ }^{88}$ The virological response during treatment appears to be promising. However, treatment is difficult due to very frequent hematological side effects. Drug-drug interactions with calcineurin inhibitors appear to be manageable by sizeable dose reduction of the calcineurin inhibitors.

\section{Beyond first-generation Pls}

Few data are available concerning second-wave PIs or other DAAs for cirrhotic patients. ${ }^{89}$ In a Phase IIb study, 83 GT-1 treatment-experienced cirrhotic patients are treated with simeprevir 100 or $150 \mathrm{mg}$ QD and PR for 12, 24, or 48 weeks, followed by PR alone up to week 48 . The SVR rates are $73 \%$ for previous relapsers, $82 \%$ for partial responders, and $31 \%$ for null responders (for those treated with $150 \mathrm{mg}$ QD); in all cases, the SVR rates are higher than in the PR arms. ${ }^{16}$

For 23 GT-1/4 naïve cirrhotic patients treated with mericitabine $1000 \mathrm{mg}$ BID and PR for 24 or 48 weeks, the SVR rate is $38 \%$ versus $22 \%$ in PR arms. ${ }^{32,33}$ However, dose 
Table 5 Estimate of first approval for the new HCV treatments in the USA and Europe

\begin{tabular}{|c|c|c|c|c|}
\hline Protease inhibitor & Company & $\begin{array}{l}\text { Current } \\
\text { clinical } \\
\text { phase }\end{array}$ & $\begin{array}{l}\text { FDA approval } \\
\text { expected }\end{array}$ & $\begin{array}{l}\text { EMEA } \\
\text { approval } \\
\text { expected }\end{array}$ \\
\hline Simeprevir TMC-435 14,15 & Tibotec & III & 2013 & 2014 \\
\hline Faldaprevir BI-20I $135^{16,17}$ & Boehringer Ingelheim & III & 2014 & 2014 \\
\hline Danoprevir (ITMN-191, RG 7227) & Roche & II & $2015 ?$ & $2015 ?$ \\
\hline Vaniprevir (MK-7009) & Merck & III & No 2014(Japon) & No \\
\hline ABT $-450^{22}$ & Abbott & III & 2014 & 2014 \\
\hline Sovaprevir ACH-I62523 & Achillion & II & $?$ & $?$ \\
\hline Asunaprevir BMS-65003224,25 & BMS & III & 2014 & 2014 \\
\hline GS-9256 & Gilead & II & $?$ & $?$ \\
\hline MK-5I72 & MSD & ॥ & $2015 / 2016$ & $2015 / 2016$ \\
\hline \multicolumn{5}{|l|}{ Polymerase inhibitors } \\
\hline RG-7|28 Mericitabine ${ }^{31-33}$ & Roche & II & $?$ & $?$ \\
\hline GS- 7977 Sofosbuvir ${ }^{34-38}$ & Gilead & III & 2013 & 2013 \\
\hline NNI-Site I inhibitors BI $207127^{39}$ & Bohringer Ingelheim & III & 2014 & 2014 \\
\hline NNI-Site I inhibitors BMS 79/32573 & BMS & II & $2014 / 2015$ & $2014 / 2015$ \\
\hline NNI-Site 2 inhibitors Filibuvir ${ }^{40}$ & Pfizer & II & $?$ & $?$ \\
\hline NNI-Site 2 inhibitors VX-222 ${ }^{41}$ & Vertex & II & $?$ & $?$ \\
\hline NNI-Site 3 inhibitors Setrobuvir & Anadys & I & $?$ & $?$ \\
\hline \multicolumn{5}{|l|}{ ANA59842 } \\
\hline NNI-Site 3 inhibitors ABT-33343 & Abbott & III & 2014 & 2014 \\
\hline NNI-Site 3 inhibitors ABT- $072^{43}$ & Abbott & II & $?$ & $?$ \\
\hline NNI-Site 4 inhibitors & Gilead & II & $?$ & $?$ \\
\hline \multicolumn{5}{|l|}{ Tegobuvir (GS9|90) ${ }^{44}$} \\
\hline \multicolumn{5}{|l|}{ NS5A-inhibitor } \\
\hline Daclatasvir (DCV) BMS-790052 $2^{46-48}$ & BMS & III & 2014 & 2014 \\
\hline ABT $267^{51}$ & Abbott & III & 2014 & 2014 \\
\hline Ledipasvir GS-5885 & Gilead & III & 2014 & 2014 \\
\hline www.clinicaltrial.gov & & & & \\
\hline
\end{tabular}

Abbreviations: EMEA, European Medicines Agency; FDA, US Food and Drug Administration; HCV, hepatitis C virus.

or duration reduction of mericitabine impairs treatment response for cirrhotic patients. An ongoing study with GT-1 cirrhotic patients receiving quadruple regimen (mericitabine, ritonavir-boosted danoprevir, and PR) is currently being conducted.

Sofosbuvir was tested initially on 8 cirrhotic (CHILDPugh B) patients for 7 days (400 mg QD). The systemic exposure was the same for cirrhotic as for noncirrhotic patients, and a significant HCV RNA decline was observed. The decline for cirrhotic patients was less impressive than in patients with mild or moderate fibrosis..$^{90}$ In the Phase III NEUTRINO study, sofosbuvir (400 mg QD) and PR for 12 weeks reaches an $80 \%$ SVR rate for 56 GT-1 cirrhotic patients.

Daclatasvir 20 or $60 \mathrm{mg}$ QD in association with PR for 24 weeks reaches a SVR rate between $57 \%$ to $62 \%$ in 20 GT-1 naïve cirrhotic patients. ${ }^{47}$

\section{INF-free regimen}

Very few INF-free regimen studies include patients with cirrhosis. In SOUND-C2, one of the largest IFN-free regimen studies, 33 naïve GT-1 cirrhotic patients are treated with faldaprevir and BI-207127 with or without RBV for 16, 28 , or 48 weeks. The SVR rates are $43 \%-50 \%$ for GT-1a patients and $57 \%-80 \%$ for GT-1b patients. ${ }^{91}$ These rates are close to those observed for the noncirrhotic population. Two Phase III studies investigate regimens with sofosbuvir $400 \mathrm{mg}$ QD and RBV for 12 weeks with GT-2 or GT-3 patients. In the POSITRON study, the SVR rate is $61 \%$ among the 31 GT-2/3 cirrhotic patients; in the FISSION study, it is $47 \%$ (100 GT-2/3 cirrhotic patients).

\section{Conclusion}

Triple therapy with first-generation PIs was a major step forward in HCV treatment for GT-1 patients. Since 2010, more than ten different DAAs are in Phase II or III development. Approximately ten more DAAs are either in preclinical or in early clinical development. Meanwhile, several studies demonstrate that IFN-free regimens are able to cure a large number of either naïve or treatment-experienced GT-1 patients. Moreover, for the most difficult-to-cure patients, quadruple regimen with PR is able to cure almost all GT-1 null responders. The development of pan-genotypic DAAs 
such as NIs or NS5A.I allows new DAA combinations with or without PR; these increase the SVR rates for all patients (even for those with cirrhosis and for all genotypes). This new regimen appears so far to be safer, and also allows shorter treatment duration. These developments appear to be another major step forward for HCV treatment. Table 5 gives an estimated period on the timing that we could expect for the molecule to be launched. In conclusion, there is hope that almost all treated patients can be cured in the near future.

\section{Disclosure}

The authors report no conflicts of interest in this work.

\section{References}

1. Lauer GM, Walker BD. Hepatitis C Virus Infection. $N$ Engl $J$ Med. 2001;345:41-52.

2. Poordad F, McCone J Jr, Bacon BR, et al. Boceprevir for untreated chronic HCV genotype 1 infection. N Engl J Med. 2011;364(13):1195-1206.

3. Jacobson IM, McHutchison JG, Dusheiko G, et al. Telaprevir for previously untreated chronic hepatitis C virus infection. $N$ Engl J Med. 2011;364(25):2405-2416.

4. Sherman KE, Flamm SL, Afdhal NH, et al. Response-guided telaprevir combination treatment for hepatitis $\mathrm{C}$ virus infection. $N$ Engl J Med. 2011;365(11):1014-1024.

5. Bacon BR, Gordon SC, Lawitz E, et al. Boceprevir for previously treated chronic HCV genotype 1 infection. NEngl J Med. 2011;364(13): $1207-1217$.

6. Zeuzem S, Andreone P, Pol S, et al. Telaprevir for retreatment of HCV infection. N Engl J Med. 2011;364(25):2417-2428.

7. Wartelle-Bladou C, Le Folgoc G, Bourliere M, Lecomte L. Hepatitis C therapy in non-genotype 1 patients: the near future. $J$ Viral Hepat. 2012;19(8):525-536.

8. Cacoub P, Bourliere M, Lubbe J, et al. Dermatological side effects of hepatitis $\mathrm{C}$ and its treatment: patient management in the era of directacting antivirals. $J$ Hepatol. 2012;56(2):455-463.

9. Sulkowski MS, Roberts S, Afdhal NH, et al. Ribavirin dose modification in treatment-naive and previously treated patients who received telaprevir combination treatment: no impact on sustained virologic response in phase 3 studies [abstract]. J Hepatol. 2012;56(Suppl 2): S459-S460.

10. Poordad F, Lawitz E, Reddy KR, et al. Timing and magnitude of ribavirin dose reduction do not impact sustained virologic response rates with boceprevir + peginterferon alfa-2b/ribavirin in the anemia management study in chronic HCV genotype 1 patients [abstract]. Hepatology. 2012;56(Suppl S1):269A-270A.

11. Lawitz E, Zeuzem S, Nyberg LM, Nelson DR, Rossaro L, Balart LA, et al. Boceprevir combined with peginterferon alfa-2b/ribavirin in treatment-naive chronic HCV genotype 1 patients with compensated cirrhosis: sustained virologic response and safety subanalyses from the anemia management study [abstract]. Hepatology. 2012; 56(Suppl):216A.

12. Ciesek S, von Hahn T, Manns MP. Second-wave protease inhibitors: choosing an heir. Clin Liver Dis. 2011;15(3):597-609.

13. Fusco DN, Chung RT. New protease inhibitors for HCV - help is on the way. J Hepatol. 2011;54(6):1087-1089.

14. Asselah T, Marcellin P. New direct-acting antivirals' combination for the treatment of chronic hepatitis C. Liver Int. 2011;31(Suppl 1):68-77.

15. Fried M, Buti M, Dore GJ, Flisiak R, Ferenci P, Jacobson IM, et al. TMC 435 in combination with peginterferon and ribavirin in treatment naive HCV genotype 1 patients: Final results of the PILLAR phase IIB study [abstract]. Hepatology. 2011;54(Suppl S1):1429A.
16. Zeuzem S, Berg T, Gane E, et al. TMC435 in HCV genotype 1 patients who have failed previous pegylated interferon ribavirin treatment: Final SVR24 results of the ASPIRE trial [abstract]. JHepatol. 2012;56(Supp12): S1-S2.

17. Sulkowski M, Ceasu E, Asselah T, et al. Silen-C1: sustained virologic response and safety of BI201335 combined with peginterferon alfa-2a and ribavirin in treatment naive patients with chronic genotype 1 infection [abstract]. J Hepatol. 2011;54(Suppl 1):S27.

18. Sulkowski M, Bourliere M, Bronowicki JP, et al. SILEN-C2: Sustained virologic response and safety of BI 201335 combined with peginterferon alfa-2A and ribavirin in chronic HCV genotype 1 patients with nonresponse to P/R [abstract]. J Hepatol. 2011;54(Suppl 1):S30.

19. Everson G, Cooper C, Hezode C, et al. Rapid and sustained achievement of undetectable HCV RNA during treatment with ritonavirboosted danoprevir/PEGIFN alfa-2A/RBV in HCV genotype 1 or 4 patients: DAUPHINE week 12 interim analysis [abstract]. J Hepatol. 2012;56(Suppl 2):S466.

20. Feld JJ, Jacobson I, Jensen DM, Foster GR, Pol S, Tam E, et al. Up to $100 \%$ SVR 4 rates with ritonavir-boosted danoprevir, mericitabine and ribavirin with or without peginterferon alfa- $2 \mathrm{a}$ in $\mathrm{HCV}$ genotype 1-infected partial and null responders: results from the MATTERHORN study [abstract]. Hepatology. 2012;56(Suppl): 231A-232A.

21. Manns MP, Gane E, Rodriguez-Torres M, et al. Vaniprevir with pegylated interferon alpha- $2 \mathrm{a}$ and ribavirin in treatment-naive patients with chronic hepatitis C: a randomized phase II study. Hepatology. 2012;56(3):884-893.

22. Lawitz E, Rodriguez-Torres M, Stoehr A, Gane EJ, Serfaty L, Bhanja S, et al. A phase 2B study of MK 7009 (vaniprevir) in patients with genotype $1 \mathrm{HCV}$ infection who have failed previous pegylated interferon and ribavirin treatment [abstract]. Hepatology. 2011;54: $1434 \mathrm{~A}-1435 \mathrm{~A}$.

23. Lawitz E, Poordad F, DeJesus E, et al. ABT-450/ritonavir combined with pegylated interferon alpha- $\mathrm{A}$ and ribavirin after 3 days monotherapy in genotype $1 \mathrm{HCV}$-infected treatment-naive subjects: 12 weeks sustained virologic response and safety results [abstract]. $J$ Hepatol. 2012;56(Suppl 2):S470.

24. Poordad F, Lalezari J, Lawitz E, Van Vlierberghe H, Shiffman ML, et al. Continued high virologic response rates with ACH-1625 daily dosing plus pegIFN-alpha-2A in a 28 days and 12 week phase 2a trial [abstract]. J Hepatol. 2012;56(Suppl 2):S455.

25. Bronowicki J-P, Pol S, Thuluvath P, et al. Asunaprevir, an NS3 protease inhibitor in combination with peginterferon and ribavirin in treatmentnaive patients with genotype 1 chronic hepatitis $\mathrm{C}$ infection [abstract]. J Hepatol. 2012;56(Suppl 2):S431-S432.

26. Lok AS, Gardiner DF, Lawitz E, et al. Preliminary study of two antiviral agents for hepatitis C genotype 1. N Engl J Med. 2012;366(3): 216-224.

27. Moreno C, Berg T, Tanwandee T, et al. A phase IIA, open label study to assess the antiviral activity of TMC435 monotherapy in patients infected with HCV genotypes 2-6. Hepatology. 2010;52(Suppl):749A-750A.

28. Hezode C, Shiffman ML, Cooper C, et al. Ritonavir-boosted danoprevir plus peginterferon alfa-2a/ribavirin demonstrates up to $100 \%$ SVR2 4 with 12 or 24 weeks of total treatment in treatment-naive patients with genotype 4 infection in the DAUPHINE study [abstract]. Hepatology. 2012;56(Suppl):557A.

29. Brainard DM, Petry A, Van Dyck K, et al. Safety and antiviral activity of MK-5172 a novel HCV NS3/4A protease inhibitors with potent activity against known resistance mutants in genotype 1 and $3 \mathrm{HCV}$-infected patients [abstract]. Hepatology. 2010;52(Suppl):706A-707A.

30. Bourliere M, Khaloun A, Wartelle-Bladou C, et al. Chronic hepatitis C: treatments of the future. Clin Res Hepatol Gastroenterol. 2011; 35 Suppl 2:S84-S95.

31. Membreno FE, Lawitz EJ. The HCV NS5B nucleoside and nonnucleoside inhibitors. Clin Liver Dis. 2011;15(3):611-626. 
32. Wedemeyer H, Jensen D, Herring R Jr, et al. Efficacy and safety of mericitabine in combination with PEG-IFN alfa-2A/RBV in G1/4 treatment naive HCV patients: Final analysis from the PROPEL study [abstract]. J Hepatol. 2012;56(Suppl 2):S481-S482.

33. Pockros P, Jensen D, Tsai N, et al. SVR-12 among G1/4 treatment-naive patients receiving mericitabine in combination with $\mathrm{PEG}-\mathrm{IFN}$ alfa-2A/ RBV: interim analysis from the JUMP-C study [abstract]. J Hepatol. 2012;56(Supp1 2):S477-S478.

34. Gane EJ, Rodriguez-Torres M, Nelson DE, et al. Sustained virologic response following RG7128 $1500 \mathrm{mg} \mathrm{BID/PEG-IFN/RBV} \mathrm{for} 28$ days in HCV genotype $2 / 3$ prior non responders [abstract]. J Hepatol. 2010;52(Suppl 1):S16.

35. Gane EJ, Stedman CA, Hyland RH, et al. Nucleotide polymerase inhibitor sofosbuvir plus ribavirin for hepatitis C. N Engl J Med. 2013;368(1): 34-44.

36. Gane EJ, Stedman CA, Hyland RH, et al. Once daily sofosbuvir (GS7977) plus ribavirin in patients with HCV genotypes 1, 2 and 3: The ELECTRON trial. Hepatology. 2012;56(Suppl):306A.

37. Lalezari J, Lawitz E, Rodriguez-Torres M, et al. Once daily PSI-7977 plus PEGIFN/RBV in a phase 2B trial: Rapid virologic suppression in treatment-naive patients with HCV GT2/GT3 [abstract]. J Hepatol. 2011;54(Suppl 1):S28.

38. Lawitz E, Gane E, Stedman C, et al. PSI-7977 PROTON and ELECTRON: $100 \%$ concordance of SV4 with SVR24 in HCV GT1, GT2 and GT3 [abstract]. J Hepatol. 2012;56(Suppl 2):S4

39. Hassanein T, Lawitz E, Crespo I, et al. Once daily sofosbuvir (GS-7977) plus PEG/RBV: high early response rates are maintained during post-treatment follow-up in treatment naive patients with HCV genotype 1, 4 and 6 infection in the ATOMIC study [abstract]. Hepatology. 2012;56(Suppl):307A.

40. Larrey D, Lohse AW, de Ledinghen V, et al. Rapid and strong antiviral activity of the non-nucleosidic NS5B polymerase inhibitor BI 207127 in combination with peginterferon alfa $2 \mathrm{a}$ and ribavirin. $J$ Hepatol. 2012;57(1):39-46.

41. Jacobson I, Pockros PJ, Lalezari J, et al. Virologic response rates following 4 weeks of filibuvir in combination with pegylated interferon alfa-2A and ribavirin in chronically-infected HCV genotype-1 patients [abstract]. J Hepatol. 2010;52(Suppl 1):S465.

42. Rodriguez-Torres M, Lawitz E, Conway B, et al. Safety and antiviral activity of the HCV non-nucleoside polymerase inhibitor VX-222 in treatment-naive genotype $1 \mathrm{HCV}$ infected patients [abstract]. J Hepatol. 2010;52(Suppl 1):S14

43. Lawitz E, Rodriguez-Torres M, Rustgi VK, et al. Safety and antiviral activity of ANA 598 in combination with pegylated interferon alfa-2A plus ribavirin in treatment-naive genotype 1 chronic $\mathrm{HCV}$ patients [abstract]. Hepatology. 2010;52(Suppl):334A-335A.

44. Poordad F, Lawitz E, DeJesus E, et al. ABT-072 or ABT-333 combined with pegylated interferon and ribavirin after 3 days monotherapy in HCV genotype 1 infected treatment-naive subjects: 12 week sustained virologic response and safety results [abstract]. J Hepatol. 2012; 56(Supp1 2):S478.

45. Lawitz E, Jacobson I, Godofsky E, et al. A phase 2B trial comparing 24 to 48 weeks treatment with tegobuvir (GS-9190)/PEG/RBV to 48 weeks treatment with PEG/RBV for chronic genotype $1 \mathrm{HCV}$ infection [abstract]. J Hepatol. 2011;54(Suppl 1):S181.

46. Suk-Fong Lok A. HCV NS5A inhibitors in development. Clin Liver Dis. 2013;17:111-121.

47. Hezode C, Hirschfield GM, Ghesquiere W, et al. Daclatasvir an NS5A replication complex inhibitor, combined with peginterferon alfa-2a and ribavirin in treatment naive HCV genotype 1 or 4 subjects: phase 2b COMMAND-1 SVR12 results [abstract]. Hepatology. 2012; 56(Suppl):553A.

48. Ratziu V, Gadano A, Pol S, et al. Triple therapy with daclatasvir, peginterferon alfa-2a and ribavirin in $\mathrm{HCV}$ infected prior null and partial responders: 12 weeks results of phase $2 \mathrm{~b}$ COMMAND-2 trial [abstract]. J Hepatol. 2012;56(Suppl 2):S478-S479.
49. Dore GJ, Lawitz E, Hezode C, et al. Twelve or 16 week treatment with daclatasvir combined with peginterferon alfa and ribavirin for hepatitis C virus genotype 2 or 3 infection: COMMAND GT2/3 study [abstract]. Hepatology. 2012;56(Supp1):558A-559A.

50. Lok AS, Gardiner DF, Hezode C, et al. Sustained virologic response in chronic HCV genotype 1-infected null responders with the combination of daclatasvir and asunaprevir with or without peginterferon alfa-2a/ribavirin [abstract]. Hepatology. 2012;56(Suppl): 230A.

51. Sulkowski MS, Gardiner DF, Rodriguez-Torres M, et al. High rate of sustained virologic response with all-oral combination of daclatasvir (NS5A inhibitor) plus sofosbuvir (Nucleotide NS5B inhibitor) with or without ribavirin, in treatment-naive patients chronically infected with HCV genotype 1,2 or 3 [abstract]. Hepatology. 2012; 56(Suppl):LB-2.

52. Sullivan GJ, Rodriguez-Torres M, Lawitz E, et al. ABT-267 combined with pegylated interferon alpha-2A and ribavirin in genotype $1 \mathrm{HCV}$ infected treatment-naive subject: 12 week antiviral and safety analysis [abstract]. J Hepatol. 2012;56(Suppl 2):S480.

53. Sulkowski MS, Rodriguez-Torres M, Lawitz E, et al. High sustained virologic response rate in treatment-naive HCV genotype $1 \mathrm{~A}$ and 1B patients treated for 12 weeks with an interferon-free all-oral quad regimen: interim results [abstract]. J Hepatol. 2012;56(Suppl 2):S560.

54. Flisiak R, Horban A, Gallay P, et al. The cyclophilin inhibitor Debio025 shows potent anti-hepatitis $\mathrm{C}$ effect in patients coinfected with hepatitis C and human immunodeficiency virus. Hepatology. 2008;47(3): 817-826.

55. Membreno FE, Espinales JC, Lawitz EJ. Cyclophilin inhibitors for hepatitis C therapy. Clin Liver Dis. 2013;17:129-139.

56. Alberti A, Chuang WL, Flisiak R, et al. Alisporivir plus peginterferon/ ribavirin in HCV genotype 1 treatment-experienced patients achieves primary endpoint with superior efficacy at treatment week $12 \mathrm{com}$ pared to retreatment with PR [abstract]. J Hepatol. 2012;56(Suppl 2): S553-S554.

57. Pawlostky J-M, Sarin SK, Foster G, et al. Alisporivir plus ribavirin is highly effective as interferon-free or interferon-add-on regimen in previously untreated HCV-GT2or GT3 patients: SVR12 results from VITAL-1 phase 2b study [abstract]. J Hepatol. 2012;56(Suppl 2):S553.

58. Wedemeyer H, Janczewska E, Wlodzimierz M, et al. Significant improvement of complete EVR in HCVAC phase II clinical trial when adding TG4040 therapeutic vaccine to PEGIFN alfa-2A and ribavirin [abstract]. J Hepatol. 2012;56(Supp1 2):S552.

59. Biermer M, Schlosser B, Fulop B, et al. High-dose silibinin rescue treatment for $\mathrm{HCV}$-infected patients showing suboptimal virologic response to standard combination therapy. J Viral Hepat. 2012;19(8): 547-553.

60. Muir AJ, Hillson JA, Gray TE, et al. Peginterferon Lambda-1a compared to peginterferon alpha-2a in treatment-naive patients with $\mathrm{HCV}$ genotype 1 or 4 . SVR24 from EMERGE phase 2b [abstract]. Hepatology. 2012;56(Suppl):299A.

61. Gane EJ, Roberts SK, Stedman CA, et al. Oral combination therapy with a nucleoside polymerase inhibitor (RG7128) and danoprevir for chronic hepatitis $\mathrm{C}$ genotype 1 infection (INFORM-1): a randomised, double-blind, placebo-controlled, dose-escalation trial. Lancet. 2010;376(9751):1467-1475.

62. Gane EJ, Pockros P, Zeuzem S, et al. Interferon-free treatment with a combination of mericitabine and danoprevir/R with or without ribavirin in treatment-naive $\mathrm{HCV}$ genotype 1 infected patients [abstract]. J Hepatol. 2012;56(Suppl 2):S555-S556.

63. Zeuzem S, Asselah T, Angus P, et al. Efficacy of the protease inhibitor BI 201335, polymerase inhibitor BI 207127, and ribavirin in patients with chronic HCV infection. Gastroenterology. 2011;141(6):2047-2055.

64. Zeuzem S, Soriano V, Asselah T, et al. SVR4 and SVR12 with an interferon-free regimen of BI201335 and BI207127 +/- ribavirin in treatment naive patients with chronic genotype $1 \mathrm{HCV}$ infection; interim results of SOUND-C2 [abstract]. J Hepatol. 2012; 56(Suppl 2):S45. 
65. Zeuzem S, Soriano V, Asselah $\mathrm{T}$, et al. Interferon-free combination treatment with HCV NS3/NS4 protease inhibitor BI201335 and the non nucleoside NS5B inhibitor BI 207127 with or without ribavirin: Final results of SOUND-C2 and predictors of response [abstract]. Hepatology. 2012;56(Suppl):308A-309A.

66. Di Bisceglie AM, Nelson DR, Gane E, et al. VX-222 with TVR alone or in combination with peginterferon alfa-2a and ribavirin in treatment naive patients with chronic hepatitis C: ZENITH study interim results [abstract]. J Hepatol. 2011;54(Suppl 1):S540.

67. Jacobson I, Sulkowski MS, Gane EJ, et al. VX-222, telaprevir and ribavirin in treatment-naive patients with genotype 1 chronic hepatitis $\mathrm{C}$ : results of the ZENITH study interferon-free regimen [abstract]. Hepatology. 2012;56(Suppl):308A.

68. Zeuzem S, Buggisch P, Agarwal K, et al. Dual, triple and quadruple combination treatment with a protease inhibitor (GS-9256) and a polymerase inhibitor (GS-9190) alone and in combination with ribavirin (RBV) or PegIFN/RBV for up to 28 days in treatment naive genotype 1 HCV subjects [abstract]. Hepatology. 2010;52(Suppl):400A.

69. Poordad F, Lawitz E, Kowdley KV, et al. 12 week interferon-free regimen of ABT-450/R + ABT-333 + ribavirin achieved SVR12 in more than $90 \%$ of treatment-naive HCV genotype 1 infected subjects and $47 \%$ of previous non-responders [abstract]. J Hepatol. 2012;56(Suppl 2): S549-S550.

70. Kowdley KV, Lawitz E, Poordad F, et al. A 12 week interferon-free treatment regimen with ABT-450/R, ABT-267, ABT-333 and ribavirin achieves a SVR12 rates (observed data) of $99 \%$ in treatment-naive patients and $93 \%$ in prior null responders with $\mathrm{HCV}$ genotype 1 infection Hepatology. 2012;56(Suppl):LB-1.

71. Lawitz E, Poordad F, Kowdley KV, et al. A 12 week interferon-free regimen of ABT-450/R, ABT-072 and ribavirin was well tolerated and achieved sustained virologic response in 91\% treatment-naive HCV IL28B-CC genotype1 infected subjects [abstract]. J Hepatol. 2012;56(Suppl 2):S7.

72. Chayama K, Takahashi S, Toyota J, et al. Dual therapy with the nonstructural protein $5 \mathrm{~A}$ inhibitor, daclatasvir, and the nonstructural protein 3 protease inhibitor, asunaprevir, in hepatitis $\mathrm{C}$ virus genotype $1 \mathrm{~b}$-infected null responders. Hepatology. 2012;55(3):742-748.

73. Sulkowski M, Gardiner D, Lawitz E, et al. Potent viral suppression with the all-oral combination of daclatasvir (NS5A inhibitor) and GS-7977 (nucleotide NS5B inhibitor +/- ribavirin in treatment-naive patients with chronic HCV GT1,2, or 3 [abstract]. J Hepatol. 2012;56(Suppl 2):S560.

74. Everson GT, Sims KD, Rodriguez-Torres M, et al. An interferonfree, ribavirin-free 12-week regimen of daclatasvir, asunaprevir and BMS-791325 yielded SVR4 of 94\% in treatment-naive patients with genotype 1 chronic hepatitis $\mathrm{C}$ virus infection [abstract]. Hepatology. 2012;56(Suppl):LB-3.

75. Nelson DR, Gane EJ, Jacobson IM, et al. VX222/Telaprevir in combination with peginterferon alfa-2A and ribavirin in treatment-naive genotype $1 \mathrm{HCV}$ patients treated for 12 weeks: ZENITH study, SVR12 interil analysis [abstract]. Hepatology. 2011;54(Suppl):1435A.

76. Hajarizadeh B,Grebely J, Dore GJ. Epidemiology and natural history of HCV infection. Nat Rev Gastroenterol Hepatol. 2013. [Epub ahead of print].

77. Marcellin $\mathrm{P}$, Cheinquer H, Curescu M, et al. Worldwide experience treating chronic hepatitis $\mathrm{C}$ with peginterferon alfa/ribavirin: Final results from 7163 naive mono-infected patients enrolled in the large multinational PROPHESYS cohort study. Hepatology. 2011; 54(Suppl):824A.

78. European Association for the Study of the Liver. EASL Clinical Practice Guidelines: management of hepatitis C virus infection. J Hepatol. 2011;55(2):245-264.

79. Foster GR, Hezode C, Bronowicki JP, et al. Telaprevir alone or with peginterferon and ribavirin reduces HCV RNA in patients with chronic genotype 2 but not genotype 3 infections. Gastroenterology. 2011;141(3):881-889. e1.

80. Benhamou Y, Moussalli J, Ratziu V, et al. Activity of telaprevir or in combination with peginterferon alfa-2a and ribavirin in treatment naive genotype 4 hepatitis $\mathrm{C}$ patients. Final results of study C210. [abstract]. Hepatology. 2010;52(Suppl):719A-720A.
81. Silva MO, Kasserra C, Gupta A, Treitel M, Hughes E, O’Mara E. Antiviral activity of boceprevir monotherapy in treatment-naive subjects with chronic hepatitis C genotype 2/3 APASL Feb 17-20, 2011. 2011;10:13-66.

82. Summa V, Ludmerer SW, McCauley JA, et al. MK-5172, a selective inhibitor of hepatitis $\mathrm{C}$ virus NS3/4a protease with broad activity across genotypes and resistant variants. Antimicrob Agents Chemother. 2012;56(8):4161-4167.

83. Paeshuyse J, Kaul A, De Clercq E, et al. The non-immunosuppressive cyclosporin DEBIO-025 is a potent inhibitor of hepatitis $\mathrm{C}$ virus replication in vitro. Hepatology. 2006;43(4):761-770.

84. Moreno C, Berg T, Tanwandee T, et al. Antiviral activity of TMC435 monotherapy in patients infected with HCV genotypes 2-6: TMC435-C202, a phase IIa, open-label study. J Hepatol. 2012;56(6):1247-1253.

85. Pockros P, Jensen D, Tsai N, et al. SVR12 among G1/4 treatement naive patients receiving mericitabine in combination with PEG-IFN alfa-2a/ ribavirin; Interim analysis from the JUMP-C study [abstract]. J Hepatol. 2012;56(Suppl 2):S477-S478.

86. Kowdley KV, Lawitz E, Crespo I, et al. ATOMIC: 97\% RVR for PSI$7977+\mathrm{PEG} / \mathrm{RBV} \times 12$ week regimen in HCV GT1: an end to responseguided therapy [abstract]? J Hepatol. 2012;56(Suppl 2):S1.

87. Hezode C, Dorival C, Zoulim F, et al. Safety and efficacy of telaprevir or boceprevir in combination with peginterferon alfa/ribavirin in 455 cirrhotic non responders. Week 16 analysis of the French early access program (ANRS CO20-CUPIC) in real-life setting [abstract]. Hepatology. 2012;56(Suppl):217A.

88. Coilly A, Roche B, Botta-Fridlund D, et al. Efficacy and safety of protease inhibitors for severe hepatitis $\mathrm{C}$ recurrence after liver transplantation: A first multicentric experience [abstract]. J Hepatol. 2012; 56(Suppl 2):S21.

89. Bourliere M, Wendt A, Fontaine H, Hezode C, Pol S, Bronowicki JP. How to optimize HCV therapy in genotype 1 patients with cirrhosis. Liver Int. 2013;33(Suppl 1):46-55.

90. Lawitz E, Rodriguez-Torres M, Cornpropst MT, et al. The effect of hepatic impairment on the pharmacokinetics and antiviral activity of PSI-7977 in hepatitis C infected subjects treated for seven days [abstract]. J Hepatol. 2012;56(Suppl 2):S445-S446.

91. Soriano V, Gane EJ, Angus PW, et al. Efficacy and safety of the interferon-free combination of BI 201335 + BI 207127 with or without ribavirin in treatment-naive patients with $\mathrm{HCV}$ genotype 1 infection and compensated liver cirrhosis: results from the SOUND-C2 study [abstract]. Hepatology. 2012;56(Suppl 1):234A.

92. Marcellin P, Manns M, Janczewska E, et al. 12 weeks response- guided treatment with the NS5A inhibitor, GS-5885, the NS3 protease inhibitor, GS-9451, plus pegylated interferon and ribavirin in treatment naive genotype 1 hepatitis C infected patients. J Hepatol. 2013;58(2):S355.

93. Thompson A, Han S, Shiffman M, et al. (2013) GS-5885 + GS- 9451 + PEGinterferon and ribavirin for six or twelve weeks achieves high SVR12 rates in treatment naive genotype1 IL28B CC patients. J Hepatol. 2013;58(2):S29.

94. Everson G, Di Bisceglie A, Vierling J, et al. (2013) Combination of the NS5A inhibitor GS-5885, the NS3 protease inhibitor GS-9451 and pegylated interferon plus riba- virin in treatment experienced patients with genotype 1 hepatitis C infection. J Hepatol. 58(2):S6.

95. Lawitz E, Ghalib R, Rodriguez-Torres M. SVR4 results of a once daily regimen of simeprevir (TMC-435) plus sofosbuvir (GS-7977) with or without ribavirin in HCV GT-1 null respon- ders. DDW Orlando May 18-21, 2013. Gastroenterology. Abstract Sa 2013;144(1):374-375.

96. Manns M, Marcellin P, Poordad F, De Araujo E, Buti M, Horsmans Y, et al. Simeprevir (TMC 435) with PEGinterferon/ribavirin for treatment of chronic HCV genotype-1 infection in treat-ment-naive patients: results from Quest -2. A phase III trial. J Hepatol. 2013;58(Suppl 1): S568.

97. Jacobson I, Dore G, Foster G, Fried M, Radu M, Rafalskiy V, et al. Simeprevir (TMC 435) with PEGinterferon/ribavirin for chronic HCV geno- type-1 infection in treatment naive patients: results from Quest-1, a phase III trial. J Hepatol. 2013;58(Suppl 1):S574.98. 
98. Zeuzem S, Berg T, Gane E et al. TMC435 in HCV genotype 1 patients who have failed previous pegylated interferon ribavirin treatment: final SVR24 results of the ASPIRE trial. J Hepatol. 2012;56(Suppl 2):S1.

99. Kowdley K, Lawitz E, Crespo I, et al. Sofosbuvir with pegylated interferon alfa-2a and ribavirin for treat- ment-naive patients with hepatitis C genotype-1 infection (ATOMIC): an open-label, randomised, multicentre phase 2 trial. Lancet. 2013;381:2100-2107.

100. Lawitz E, Gane E, Stedman C, et al. PSI-7977 proton and electron: $100 \%$ concordance of SV4 with SVR24 in HCV GT1, GT2 and GT3. J Hepatol. 2012;56(Suppl 2):S4.

101. Lawitz E, Lalezari J, Hassanein T, et al. Sofosbuvir in combination with peginterferon alfa-2a and ribavirin for non-cirrhotic, treatment-naive patients with geno- types 1, 2, and 3 hepatitis $C$ infection: a randomised double-blind, phase 2 trial. Lancet Infect Dis 13. 2013:401-408.

102. Lawitz E, Mangia A, Wyles D, et al. Sofosbuvir for previously untreated chronic hepatitis C infection. N Engl J Med. 2013. 368:1878-1887.

103. Rodriguez-Torres M, Lawitz E, Kowdley K, et al. Sofosbuvir (GS-7977) plus peginterferon/ribavirin in treatment-naive patients with HCV genotype 1: a randomized, 28-day, dose-ranging trial. J Hepatol. 2013:58:663-668.

104. Gane E, Stedman C, Hyland R, et al. Nucleotide polymerase inhibitor sofosbuvir plus riba- virin for hepatitis C. N Engl J Med. 2013;368: 34-44.

105. Gane E, Stedman C, Hyland R, et al. All-oral sofosbuvir- based 12 week regimen for the treatment of chronic $\mathrm{HCV}$ infection: the Electron study. J Hepatol. 2013;58(Suppl. 1):S6-S7.
106. Lawitz, E, Ghalib R, Rodriguez-Torres M. SVR4 results of a once daily regimen of simeprevir (TMC-435) plus sofosbuvir (GS-7977) with or without ribavirin in HCV GT-1 null respon-ders. DDW Orlando. 2013;18-21.

107. Marcellin P, Manns M, Janczewska E, et al. 12 weeks responseguided treatment with the NS5A inhibitor, GS-5885, the NS3 protease inhibitor, GS-9451, plus pegylated interferon and ribavirin in treatment naive genotype 1 hepatitis $\mathrm{C}$ infected patients. $J$ Hepatol. 2013;58(Suppl 2): S355.

108. Thompson A, Han S, Shiffman M, et al. GS-5885 p GS- 9451 p PEG interferon and ribavirin for six or twelve weeks achieves high SVR12 rates in treatment naive genotype 1 IL28B CC patients. J Hepatol. 2013;58(Suppl 2):S29.

109. Everson G, Di Bisceglie A, Vierling J, et al. Combination of the NS5A inhibitor GS-5885, the NS3 protease inhibitor GS-9451 and pegylated interferon plus riba-virin in treatment experienced patients with genotype 1 hepatitis $\mathrm{C}$ infection. $J$ Hepatol. 2013;58(Suppl 2):S6.

110. Sulkowski M, Gardiner D, Lawitz E, et al. Potent viral suppression with the all-oral combination of daclatas-vir (NS5A inhibitor) and GS-7977 (nucleotide NS5B inhibitor p/- ribavirin in treatment-naive patients with chronic HCV GT1,2, or 3. J Hepatol. 2012;56:S560.

111. Sulkowski M, Gardiner D, Rodriguez-Torres M, et al. Sustained virologic response with daclatasvir plus sofosbuvir with or without ribavirin in chronic HCV genotype 1 infected patients who previously failed tel-aprevir or borceprevir. J Hepatol. 2013;58(Suppl 2): S570.
Clinical Pharmacology: Advances and Applications

\section{Publish your work in this journal}

Clinical Pharmacology: Advances and Applications is an international, peer-reviewed, open access journal publishing original research, reports, reviews and commentaries on all areas of drug experience in humans. The manuscript management system is completely online and includes a very quick and fair peer-review system, which is all easy to use.

\section{Dovepress}

Visit http://www.dovepress.com/testimonials.php to read real quotes from published authors. 